\title{
Chelation of Thallium (III) in Rats Using Combined Deferasirox and Deferiprone Therapy
}

\author{
Samie Salehi, Amir Sh. Saljooghi, Somayeh Badiee and Mojtaba Mashmool Moqadam \\ Department of Chemistry, Ferdowsi University of Mashhad, Faculty of Science, Mashhad 91775-1436, Iran
}

\begin{abstract}
Thallium and its compounds are a class of highly toxic chemicals that cause wide-ranging symptoms such as gastrointestinal disturbances; polyneuritis; encephalopathy; tachycardia; skin eruptions; hepatic, renal, cardiac, and neurological toxicities; and have mutagenic and genotoxic effects. The present research aimed to evaluate the efficacy of the chelating agents deferasirox (DFX) and deferiprone (L1) in reducing serum and tissue thallium levels after the administration of thallium (III), according to two different dosing regimens, to several groups of Wistar rats for 60 days. It was hypothesized that the two chelators might be more efficient as a combined therapy than as monotherapies in removing thallium (III) from the rats' organs. The chelators were administered orally as either single or combined therapies for a period of 14 days. Serum and tissue thallium (III) and iron concentrations were determined by flame atomic absorption spectroscopy. Serum and tissue thallium (III) levels were significantly reduced by combined therapy with DFX and L1. Additionally, iron concentrations returned to normal levels and symptoms of toxicity decreased.
\end{abstract}

Key words: Thallium (III), Chelation therapy, Deferasirox, Deferiprone, Toxic metal, Serum

\section{INTRODUCTION}

Currently, thallium is used in the manufacture of electronic components, optical lenses, semiconductor materials, alloys, gamma radiation detection equipment, imitation jewelry, artist's paints, low temperature thermometers, and green fireworks (1). It is also used in trace amounts as a contrast agent in the visualization of cardiac function and tumors. Thallium exposure may occur in smelters during the maintenance and cleaning of ducts and flues, and through contamination of cocaine, heroin, and herbal products. Criminal and unintentional thallium poisonings are still

Correspondence to: Amir Sh. Saljooghi, Department of Chemistry, Ferdowsi University of Mashhad, Faculty of Science, Mashhad 91775-1436, Iran

E-mail: saljooghi@um.ac.ir

Abbreviations: DFX, Deferasirox; L1, Deferiprone; DFO, Desferrioxamine; BCT, Before chelation therapy; WCT, Without chelation therapy; CT, Chelation therapy; TIBC, Total iron binding capacity; TS, Transferrin saturation.

This is an Open-Access article distributed under the terms of the Creative Commons Attribution Non-Commercial License (http:// creativecommons.org/licenses/by-nc/3.0) which permits unrestricted non-commercial use, distribution, and reproduction in any medium, provided the original work is properly cited. reported, some leading to death (2).

Thallium poisoning is one of the most complex and serious toxicities known to man (3). The symptomatology of its toxicity is usually nonspecific due to multi-organ involvement. The initial signs of thallium poisoning may include fever, abdominal pain, cramps, constipation, delirium, convulsions, coma, cardiotoxic and neurotoxic effects, mutagenesis, and genotoxic effects. (4). One possible mechanism of thallium toxicity is through the formation of a ligand with blood protein $(5,6)$. In humans, the most specific sign of chronic thallium toxicity is alopecia, which usually appears in cases where death is delayed for 15 20 days. Thallium excretion via the kidney can increase upon administration of potassium chloride or diuretics. Potassium therapy is one of the most effective approaches in the treatment of thallium poisoning (7). In one specific study, Abdel-Daim and Abdou reported the treatment of thallium toxicity in a biological system using other antioxidants. Their study focused on the protective and antioxidant effects of diallyl sulfide and curcumin against thallium-induced liver injury and oxidative stress in rats (8). Additionally, recently, Riyaz et al. reported an interesting case involving a suicidal patient treated for thallium toxicity using the antidote Prussian Blue (9).

Some researchers have emphasized removing toxic compounds, such as thallium, from the body by chelation ther- 
<smiles>Cc1c(O)c(=O)ccn1C</smiles>

Deferiprone

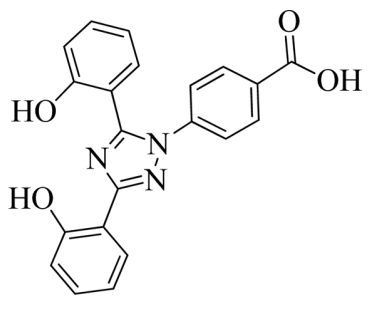

Deferasirox
Fig. 1. Two chelating agents used for the treatment of iron overload.

apy. Chelation therapy involves the use of ligand drugs with strong metal-binding tendencies for the treatment of potentially serious conditions. These chelating ligands (Fig. 1) may be bidentate (deferiprone: L1), tridentate (deferasirox: DFX), or hexadentate (desferrioxamine: DFO) $(10,11)$. DFX and L1 are the most widely used chelators for the treatment of iron overload. DFX (4-[3,5-bis(2-hydroxyphenyl)-1,2,4-triazol-1-yl]-benzoic acid, or ICL670) was first reported in 1999 (12). It is a tridentate chelator with a high selectivity for $\mathrm{Fe}^{3+}$ ions (13). In 2005, DFX became the first FDA-approved oral treatment for iron overload, and it was subsequently approved in the EU in 2006 (14). Clinical trials with deferiprone have been carried out in several countries in iron-overloaded patients, and its efficacy has been found to be comparable with that of DFO (15). L1 is water soluble, less toxic than DFO, and can be administered orally. At the same time, L1 is also more lipid soluble and can enter cells (16).

In this study, we report the chelation potency of DFX and L1 as single and combination therapies, administered to animals after thallium loading. In addition, thallium's effects on iron metabolism were investigated by monitoring the $\mathrm{Tl}$ (III) concentration in serum. Testing was performed using an acute experimental model in rats, with the chelators being administered shortly after thallium administration. This study revealed that this experimental procedure might be useful for the preliminary testing of chelating agents, to determine whether these chelators can bind and promote the removal of thallium from the organs of rats and return the serum iron content to normal levels.

\section{MATERIALS AND METHODS}

Apparatus. Varian atomic absorption spectrometers (FAAS and GF AAS) were used for measurement of thallium and iron concentrations in various organs. A Mettler analytical balance model AE 160 was also used in this research.

Maintenance of the animals. Seven-week-old male Wistar rats with an initial mean body weight of $200 \mathrm{~g}$ were housed individually in plastic cages with glass gridded bottoms and maintained under conditions of controlled tem- perature $\left(23 \pm 1^{\circ} \mathrm{C}\right)$, humidity $(55 \%)$, and light/dark cycle $(12 / 12 \mathrm{hrs})$. The rats were bred in the animal house at the Mashhad University of Medical Science, Mashhad, Iran. This study was approved by the ethics committee of Ferdowsi University of Mashhad, Mashhad, Iran and Mashhad University of Medical Science, Mashhad, Iran.

Chemicals. DFX (CAS Number: 201530-41-8, 99.5\%) was purchased from Novartis Co (Basel, Switzerland). L1 (CAS Number: 30652-11-0, 98\%) and thallium (III) chloride tetrahydrate (CAS Number: 13453-33-3, 98\%) were purchased from Sigma-Aldrich (USA).

Experimental design. For our model, we used two different doses of thallium (III) ions followed by an early administration of the chelating agents. Experiments were performed on 7-week-old male Wistar rats. Thallium was administered to these rats at two doses: $20 \mathrm{mg} \mathrm{Tl}^{3+} / \mathrm{kg}$ (low dose group) and $40 \mathrm{mg} \mathrm{Tl} l^{3+} / \mathrm{kg}$ (high dose group). Oral administration of the toxic metal ion was performed once a day. The dosing volume for the rats was calculated based on their weight. Signs of toxicity gradually appeared over the period of thallium administration. After 60 days, low and high dose groups were divided into five sub-groups: (1) before chelation therapy; (2) without chelation therapy; (3) DFX monotherapy; (4) L1 monotherapy; and (5) DFX + L1 combination therapy. In order to compare the thallium and iron concentrations in tissues before and after the chelation therapy, one group was selected as the before chelation therapy group (vehicle). The rats in this group were anaesthetized with ether vapors and were killed. Samples of the kidney, heart, intestine, liver, and spleen were weighed, dried, and collected for determination of thallium and iron content. The samples were placed in an oven at $60^{\circ} \mathrm{C}$ for 3 days. They were then digested using $1.5 \mathrm{~mL} \mathrm{HNO}_{3}$ per $1 \mathrm{~g}$ of dry weight. After digestion, the solutions were evaporated under a hood with the addition of $1.0 \mathrm{~mL} \mathrm{H}_{2} \mathrm{O}_{2}$. The residue was then diluted with water to $100 \mathrm{~mL}$. In addition, rats were sacrificed by exsanguination from the abdominal aorta and blood samples were collected. Thallium and iron concentrations in the various organs and serum were measured by Varian atomic absorption spectrometers (FAAS and GF AAS).

To investigate the removal of thallium from the rats' organs over time, a without chelation therapy group was designed, while chelation therapy with DFX and L1 was administered to assess their effects. Chelators were administered orally immediately after thallium administration for 14 days. The doses of DFX and L1 used were 140 and $300 \mathrm{mg} / \mathrm{kg}$ body weight, respectively. Thallium toxicity symptoms observed in the rats decreased in the short term after drug administration.

Statistical analysis. Determination of thallium and iron in samples was carried out by atomic absorption spec- 
trometry using the standard addition method. The values were expressed as mean (at least three separate determinations) \pm standard error of the mean (SEM). The data were subjected to statistical analysis by Student's $t$-test; $p<0.05$ was considered significant.

\section{RESULTS}

After thallium administration, abnormal clinical signs in the rats included darkening of the eyes; yellowish discoloration of hair; flaccid, hypotonic muscles; irritability; weakness; and loss of hair and body weight. There were slight differences between the groups in the initial body weight of the rats (mean $200 \mathrm{~g}$ ), but by the end of the thallium administration experiment, those administered thallium through their diet exhibited a significant weight loss (Table 1).

The final body weight of rats (day 60) in the control, low dose thallium, and high dose thallium groups was $270 \pm 7 \mathrm{~g}$, $245 \pm 8 \mathrm{~g}$, and $215 \pm 7 \mathrm{~g}$, respectively. Comparisons of the weights reveal that dietary treatment affected food intake, whereby animals fed a normal diet consumed more food than those administered thallium. Additionally, because of the slight (but significant) differences in body weight of the rats at the start of the study, the results may have been influenced by the initial classification and assignment of rats to the treated groups, a possibility that must be considered. It should be noted that after the acclimatization of the rats, they were randomly assigned to control and treated groups.
The results of thallium determinations for the different groups and organs are summarized in Table 2.

The greatest thallium accumulation was found in the kidney, followed by the liver and spleen (Table 2). Furthermore, iron concentration after thallium administration significantly decreased. The difference between iron values before and after chelation therapy is notable. The combination of DFX and L1 was more effective in returning iron levels to normal. The iron concentrations before and after chelation therapies are summarized in Table 3.

Effects of thallium on serum in rats. Serum thallium concentrations increased during the period of its administration, while iron levels decreased. Furthermore, our results showed that thallium concentrations in blood were higher for those rats receiving the higher dose than those receiving the lower dose. After the chelation therapy, serum thallium levels in both dose groups reduced significantly, and symptoms disappeared. The dietary thallium concentration had a significant effect on iron status, as shown by serum iron analysis. Serum iron concentration was the lowest in the group receiving the higher thallium dose, probably due to significant interference by thallium in the iron uptake mechanism. The data presented show that increasing doses of thallium caused a progressive increase in total iron binding capacity (TIBC). The significantly higher TIBC was observed in all groups receiving dietary thallium in comparison with that in the control group. The rate of transferrin saturation

Table 1. Body weights over 60 days for rats in different groups (values in parentheses are the number of animals in each group)

\begin{tabular}{lccc}
\hline \hline Group & Control & Low dose drinking of thallium & High dose drinking of thallium \\
\hline Initial body weight $^{\mathrm{a}}(\mathrm{g})$ & $205 \pm 7(8)$ & $200 \pm 4(8)$ & $195 \pm 3(8)$ \\
Final body weight $^{\mathrm{a}}(\mathrm{g})$ & $270 \pm 7(8)$ & $245 \pm 8(8)$ & $215 \pm 7(8)$ \\
\hline
\end{tabular}

${ }^{\mathrm{a}}$ Mean of five determination \pm standard deviation.

Table 2. Concentration of thallium $(\mathrm{mg} / \mathrm{kg})$ in control, low, and high dose groups

\begin{tabular}{|c|c|c|c|c|c|}
\hline Group & Heart & Kidney & Liver* & Intestine & Spleen \\
\hline Control & $0.069 \pm 0.003$ & $0.325 \pm 0.011$ & $0.420 \pm 0.015$ & $0.289 \pm 0.021$ & $0.306 \pm 0.014$ \\
\hline \multicolumn{6}{|l|}{ Low dose } \\
\hline BCT & $0.110 \pm 0.002$ & $0.741 \pm 0.015$ & $1.078 \pm 0.021$ & $0.685 \pm 0.026$ & $0.716 \pm 0.026$ \\
\hline WCT & $0.107 \pm 0.002$ & $0.719 \pm 0.018$ & $1.053+0.021$ & $0.659 \pm 0.029$ & $0.703 \pm 0.028$ \\
\hline CT with DFX & $0.074 \pm 0.002$ & $0.402 \pm 0.019$ & $0.602 \pm 0.023$ & $0.349 \pm 0.023$ & $0.509 \pm 0.022$ \\
\hline CT with L1 & $0.082 \pm 0.002$ & $0.418 \pm 0.024$ & $0.701 \pm 0.021$ & $0.421 \pm 0.027$ & $0.567 \pm 0.027$ \\
\hline Combined therapy & $0.069 \pm 0.004$ & $0.345 \pm 0.021$ & $0.407 \pm 0.023$ & $0.278 \pm 0.015$ & $0.324 \pm 0.025$ \\
\hline \multicolumn{6}{|l|}{ High dose } \\
\hline $\mathrm{BCT}$ & $0.143 \pm 0.003$ & $1.174 \pm 0.021$ & $1.165 \pm 0.023$ & $0.925 \pm 0.035$ & $1.142 \pm 0.027$ \\
\hline WCT & $0.139 \pm 0.003$ & $1.168 \pm 0.024$ & $1.122 \pm 0.025$ & $0.902 \pm 0.032$ & $1.138 \pm 0.023$ \\
\hline CT with DFX & $0.085 \pm 0.002$ & $0.552 \pm 0.024$ & $0.610 \pm 0.028$ & $0.501 \pm 0.024$ & $0.691 \pm 0.025$ \\
\hline CT with L1 & $0.092 \pm 0.002$ & $0.591 \pm 0.023$ & $0.722 \pm 0.027$ & $0.609 \pm 0.021$ & $0.755 \pm 0.024$ \\
\hline Combined therapy & $0.070 \pm 0.002$ & $0.322 \pm 0.023$ & $0.421 \pm 0.018$ & $0.284 \pm 0.032$ & $0.343 \pm 0.027$ \\
\hline
\end{tabular}

The number of rats in each group was five; results are represented as arithmetic mean \pm SEM. *Significant at $p<0.05$ when compared with control. BCT: before chelation therapy, WCT: without chelation therapy, CT: chelation therapy. 
Table 3. Concentration of iron ( $\mathrm{mg} / \mathrm{kg})$ in control, low, and high dose groups

\begin{tabular}{|c|c|c|c|c|c|}
\hline Group & Heart & Kidney & Liver* & Intestine & Spleen \\
\hline Control & $6.25 \pm 0.33$ & $4.71 \pm 0.28$ & $6.19 \pm 0.33$ & $3.39 \pm 0.31$ & $4.23 \pm 0.31$ \\
\hline \multicolumn{6}{|l|}{ Low dose } \\
\hline $\mathrm{BCT}$ & $4.32 \pm 0.26$ & $3.35 \pm 0.31$ & $4.61 \pm 0.29$ & $2.51 \pm 0.28$ & $3.43 \pm 0.28$ \\
\hline WCT & $4.34 \pm 0.28$ & $3.37 \pm 0.33$ & $4.63 \pm 0.25$ & $2.53 \pm 0.30$ & $3.35 \pm 0.33$ \\
\hline CT with DFX & $5.12 \pm 0.31$ & $3.68 \pm 0.28$ & $5.11 \pm 0.25$ & $3.11 \pm 0.25$ & $3.65 \pm 0.25$ \\
\hline CT with L1 & $4.83 \pm 0.30$ & $3.48 \pm 0.29$ & $4.91 \pm 0.30$ & $2.70 \pm 0.26$ & $3.51 \pm 0.33$ \\
\hline Combined therapy & $6.34 \pm 0.43$ & $4.35 \pm 0.30$ & $5.89 \pm 0.24$ & $3.59 \pm 0.25$ & $4.29 \pm 0.15$ \\
\hline \multicolumn{6}{|l|}{ High dose } \\
\hline $\mathrm{BCT}$ & $4.06 \pm 0.23$ & $3.13 \pm 0.25$ & $4.02 \pm 0.25$ & $2.09 \pm 0.25$ & $3.03 \pm 0.25$ \\
\hline WCT & $4.08 \pm 0.25$ & $3.15 \pm 0.28$ & $4.01 \pm 0.28$ & $2.11 \pm 0.28$ & $3.06 \pm 0.29$ \\
\hline CT with DFX & $5.39 \pm 0.25$ & $3.79 \pm 0.28$ & $5.25 \pm 0.27$ & $3.23 \pm 0.31$ & $3.75 \pm 0.30$ \\
\hline CT with L1 & $4.91 \pm 0.27$ & $3.58 \pm 0.29$ & $5.02 \pm 0.31$ & $2.83 \pm 0.28$ & $3.59 \pm 0.33$ \\
\hline Combined therapy & $6.28 \pm 0.39$ & $4.53 \pm 0.24$ & $6.12 \pm 0.17$ & $3.78 \pm 0.29$ & $4.08 \pm 0.33$ \\
\hline
\end{tabular}

The number of rats in each group was five; results are represented as arithmetic mean \pm SEM. *Significant at $p<0.05$ when compared with control. BCT: before chelation therapy, WCT: without chelation therapy, CT: chelation therapy.

(TS) was subsequently calculated using the following equation:

Transferrin saturation $(\%)$

$=\operatorname{serum}$ Fe concentration $(\mu \mathrm{g} / \mathrm{L}) / \mathrm{TIBC}(\mu \mathrm{g} / \mathrm{L}) \times 100$.

The saturation of transferrin with iron ions depended on the presence of thallium in the diet, and was markedly lower in the two groups that consumed thallium in their drinking water when compared with that in the control group. Additionally, our results show that the saturation of transferrin in the blood was less at the higher thallium dose than at the lower dose.

Effects of chelation on thallium-induced toxicity. Combination therapy with DFX and DFP significantly decreased the serum thallium level. Simultaneously, iron concentrations returned to normal levels, and the symptoms of thallium toxicity also decreased. These results confirm that the presence of the toxic metal interrupted iron metabolism in rats and caused symptoms of anemia to appear. The results passed the $t$-test at the $95 \%$ confidence level and were significant. At the end of the experimental period, all hematologic parameters studied in the control rats, namely, serum $\mathrm{Fe}$, serum ferritin, transferrin saturation, and TIBC, were within normal limits.

\section{DISCUSSION}

The increased use of heavy metals since the industrial revolution has resulted in a predictable increase in the number of patients who are poisoned by them $(17,18)$. Chelation therapy is one way to eliminate these metal ions from biological systems. Nowadays, different chelators are being used for this purpose. Currently, combination therapy with L1 and DFO, which are highly selective for iron (III) under biological conditions $\left(\mathrm{pFe}^{3+}=26.6\right.$ ), is reported to be the most effective treatment for many patients $(19,20)$. Undoubtedly, DFX, possessing a higher $\mathrm{pFe}^{3+}$ value than $\mathrm{L} 1$ does, behaves in a similar manner. Recently, successful chelation therapy using both DFX and L1 was reported (21). In order for a chelating agent to exert its pharmacological effect, it must be able to reach its target site at a sufficient concentration. Each chelator (DFX and L1) has a different target tissue; therefore, combining them may help to remove thallium from several tissues simultaneously.

DFX and L1 are oral chelators that are commonly used in cases of iron overload. DFX binds to metal ions in a 2:1 ratio and forms a hexadinated complex, whereas L1 forms complexes in a 3:1 ratio to reduce ion concentrations in the human body.

Interactions between thallium and iron have not previously been reported. It is not clear whether thallium interferes with iron absorption and/or its subsequent metabolism, but this could take place along pathways for essential metals (22). If this is the case, iron deficiency could result in increased absorption, as is observed for several inorganic elements such as manganese, cobalt, lead, cadmium, gallium, and indium $(23,24)$. Therefore, thallium seems to interfere with the iron uptake and transfer mechanism. Our results demonstrate the harmful effect of thallium on iron metabolism in rats. Dietary thallium, consumed in quantities of $20 \mathrm{mg} \mathrm{Tl}^{3+} \mathrm{kg}$ body weight (low dose) and $40 \mathrm{mg}$ $\mathrm{Tl}^{3+} / \mathrm{kg}$ body weight (high dose) caused a decrease in the apparent absorption of iron, which was accompanied by a decrease in serum iron concentrations and the development of anemia. Our results in Table 4 verify the occurrence of iron deficiency anemia in the rats.

In this study, we investigated the effect of thallium toxicity using two doses in different groups of rats. The efficiency of DFX as a monotherapy in removing $\mathrm{Tl}^{3+}$ ions from tis- 
Table 4. Serum indices in the experimental groups after $\mathrm{TI}^{3+}$ and DFX + DFP administration

\begin{tabular}{lccc}
\hline \hline Hematological indices & Control & Low dose drinking of thallium* & High dose drinking of thallium \\
\hline & \multicolumn{2}{c}{ After Thallium administration } \\
\hline Serum iron $(\mu \mathrm{g} / \mathrm{dL})$ & $138.65 \pm 12.62$ & $90.28 \pm 6.35$ & $67.40 \pm 5.20$ \\
TIBC $(\mu \mathrm{g} / \mathrm{dL})$ & $284.34 \pm 23.18$ & $167.21 \pm 23.56$ & $178.78 \pm 31.47$ \\
TS $(\%)$ & $47.52 \pm 7.19$ & $5.23 \pm 0.49$ & $3.93 \pm 0.49$ \\
Serum ferritin $(\mu \mathrm{g} / \mathrm{dL})$ & $82.52 \pm 2.71$ & $55.18 \pm 1.23$ & $48.362 \pm 1.76$ \\
\hline & After chelation therapy with DFX $+\mathrm{L} 1$ & $137.95 \pm 11.73$ \\
\hline Serum iron $(\mu \mathrm{g} / \mathrm{dL})$ & $138.65 \pm 12.62$ & $134.28 \pm 11.22$ & $284.68 \pm 25.43$ \\
TIBC $(\mu \mathrm{g} / \mathrm{dL})$ & $284.34 \pm 23.18$ & $278.65 \pm 24.75$ & $47.99 \pm 7.36$ \\
TS $(\%)$ & $47.52 \pm 7.19$ & $45.96 \pm 7.63$ & $82.75 \pm 2.68$ \\
Serum ferritin $(\mu \mathrm{g} / \mathrm{dL})$ & $82.52 \pm 2.71$ & $80.47 \pm 2.99$ &
\end{tabular}

Results are presented as arithmetic mean \pm SEM. *Significant at $p<0.05$ when compared with control.

sues was reported previously (25). Accordingly, we hypothesize that the accumulation of thallium in the rats' organs led to a decrease in iron concentration in these tissues and serum due to thallium's interference with iron absorption and/or subsequent metabolism. Removal of thallium was effected using chelation therapy. The aim of this study was to investigate the efficiency of DFX and L1 individually and as a combined thallium-chelating therapy. Comparisons between the results obtained with and without chelation therapies indicated that combined therapy $(\mathrm{DFX}+\mathrm{L} 1)$ enhanced the removal of thallium from the organs and serum of the studied rats. We also confirmed that tissue and serum iron levels reduced significantly after thallium administration.

The results obtained following chelation therapy indicated that the concentration of thallium present in all tissues and serum was significantly reduced, and that signs of toxicity also decreased. There is a statistical difference between DFX and L1 in their abilities to decrease thallium content in various tissues. When we compared the individual efficacies of the chelators used in this study, DFX was found to be more effective in decreasing thallium levels in the heart, intestine, and spleen; whereas L1 was more effective in the kidneys and liver. Comparisons of the single and combined therapies show the combined group (DFX + L1) to be more effective in reducing the thallium concentration in all tissues. The difference between iron concentrations before and after chelation therapies is remarkable. Iron concentration was lower in the group that had the highest thallium level, probably due to interference by thallium in the iron uptake mechanism. In addition, iron concentration after chelation therapy significantly increased, and returned to its normal state. From previous studies (26-29) and trial results, it can be concluded that the two chelators (DFX+ L1) were more effective as a combined therapy than as single-agent therapies in the removal of thallium from the body. Therefore, the DFX + L1 combination can be considered for preliminary testing as chelation therapy in thallium toxicity cases.
In this study, we tested the potencies of DFX and L1 as single and combination chelating agents, administered to animals after thallium loading. Testing was performed using an acute experimental model in rats, with individual or combined chelators administered shortly after thallium administration. Chelation is a useful technique for removing toxic metals from the body, and can be performed as single- or multiple-agent therapy. Combinations of drugs have advantages over monotherapy, including the use of lower drug dosages with consequently fewer side effects, different mechanisms of action of drugs within tissues, and lower cost. Our results confirm that combined therapy eliminated thallium from rats' organs and ameliorated the side effects and general symptoms of thallium toxicity caused by this toxic metal better than did treatment with the agents individually.

\section{ACKNOWLEDGMENTS}

This work was supported by grant number 3.24156, from Ferdowsi University of Mashhad, Mashhad, Iran. We are grateful for the help provided by the Buali Research Institute, Faculty of Pharmacy, Mashhad University of Medical Sciences, Mashhad, Iran.

\section{CONFLICT OF INTEREST}

The authors declare that there is no conflict of interest.

Received February 20, 2017; Revised April 6, 2017; Accepted July 7, 2017

\section{REFERENCES}

1. Ryu, H.W., Lee, D.H., Won, H., Kim, K.H., Seong, Y.J. and Kwon, S.H. (2015) Influence of toxicologically relevant metals on human epigenetic regulation. Toxicol. Res., 31, 1-9.

2. Lan, C.H. and Lin, T.S. (2005) Acute toxicity of trivalent thallium compounds to Daphnia magna. Ecotoxicol. Environ. Saf., 
61, 432-435.

3. Hoffman, R.S. (2003) Thallium toxicity and the role of Prussian blue in therapy. Toxicol. Rev., 22, 29-40.

4. Rodriguez-Mercado, J.J. and Altamirano-Lozano, M.A. (2013) Genetic toxicology of thallium: a review. Drug Chem. Toxicol., 36, 369-383.

5. Xiao, T., Guha, J., Boyle, D., Liu, C.Q. and Chen, J. (2004) Environmental concerns related to high thallium levels in soils and thallium uptake by plants in southwest Guizhou, China. Sci. Total Environ., 318, 223-244.

6. Peter, A.L. and Viraraghavan, T. (2005) Thallium: a review of public health and environmental concerns. Environ. Int., 3, 493-501.

7. Atlas, E., Fishbein, L., Giam, C.S., Leonard, J.E., Muir, D.C.G., Powers, M.A., Jr. and Schoer, J. (1984) Handbook of environmental chemistry; volume 3 part C. (Hutzinger, O. Ed.). Springer-Verlag, New York, pp. 143-214.

8. Abdel-Daim, M.M. and Abdou, R.H. (2015) Protective effects of diallyl sulfide and curcumin separately against thalliuminduced toxicity in rats. Cell J., 17, 379-388.

9. Riyaz, R., Pandalai, S.L., Schwartz, M. and Kazzi, Z.N. (2013) A fatal case of thallium toxicity: challenges in management. J. Med. Toxicol., 9, 75-78.

10. Clarke, E.T. and Martell, A. E. (1992) Stabilities of 1,2dimethyl-3-hydroxy-4-pyridinone chelates of divalent and trivalent metal ions. Inorg. Chim. Acta, 191, 57-63.

11. Gomez, W., Esparza, J.L., Domingo, J.L., Corbella, J., Singh, P.K. and Jones, M.M. (1998) Aluminium distribution and excretion: a comparative study of a number of chelating agents in rats. Pharmacol. Toxicol., 82, 295-300.

12. Heinz, U., Hegetschweiler, K., Acklin, P., Faller, B., Lattmann, R. and Schnebli, H.P. (1999) 4-[3,5-Bis (2-hydroxyphenyl)-1,2,4-triazol-1-yl]- benzoic acid: a novel, efficient and selective iron (III) complexing agent. Angew. Chem. Int. Ed., 38, 2568-2570.

13. Steinhauser, S., Heinz, U., Bartholomä, M., Weyhermüller, T., Nick, H. and Hegetschweiler, K. (2004) Complex formation of ICL670 and related ligands with $\mathrm{Fe}^{\mathrm{III}}$ and $\mathrm{Fe}^{\mathrm{II}}$. Eur. J. Inorg. Chem., 2004, 4177-4192.

14. Yang, L.P.H., Keam, S.J. and Keating, G.M. (2007) Deferasirox: a review of its use in the management of transfusional chronic iron overload. Drugs, 67, 2211-2230.

15. Kontoghiorghes, G.J. (1995) New concepts of iron and aluminium chelation therapy with oral L1 (deferiprone) and other chelators. A review. Analyst, 120, 845-851.

16. Liu, Z.D. and Hider, R.C. (2002) Design of iron chelators with therapeutic application. Coord. Chem. Rev., 232, 151-171.
17. Tenenbein, M. (2005) Unit-dose packaging of iron supplements and reduction of iron poisoning in young children. Arch. Pediatr. Adolesc. Med., 159, 557-560.

18. Eom, S.Y., Lim, J.A., Kim, Y.D., Choi, B.S., Hwang, M.S., Park, J.D., Kim, H. and Kwon, H.J. (2016) Allele frequencies of the single nucleotide polymorphisms related to the body burden of heavy metals in the korean population and their ethnic differences. Toxicol. Res., 32, 195-205.

19. Galanello, R., Agus, A., Campus, S., Danjou, F., Giardina, P.J. and Grady, R.W. (2010) Combined iron chelation therapy. Ann. N. Y. Acad. Sci., 1202, 79-86.

20. Salehi, S., Saljooghi, A.S. and Shiri, A. (2016) Synthesis, characterization and in vitro anticancer evaluations of two novel derivatives of deferasirox iron chelator. Eur. J. Pharmacol., 781, 209-217.

21. Voskaridou, E., Christoulas, D. and Terpos, E. (2011) Successful chelation therapy with the combination of deferasirox and deferiprone in a patient with thalassaemia major and persisting severe iron overload after single-agent chelation therapies. Br. J. Haematol., 154, 654-656.

22. Harriss, W.R. and Messori, L. (2002) A comparative study of aluminum(III), gallium(III), indium(III), and thallium(III) binding to human serum transferrin. Coord. Chem. Rev., 228, 237-262.

23. Saljooghi, A.S. and Fatemi, S.J. (2010) Clinical evaluation of Deferasirox for removal of cadmium ions in rat. Biometals, 23, 707-712.

24. Balooch, F.D., Fatemi, S.J. and Iranmanesh, M. (2014) Combined chelation of lead (II) by deferasirox and deferiprone in rats as biological model. BioMetals, 27, 89-95.

25. Saljooghi, A.S. and Fatemi, S.J. (2010) Removal of thallium by deferasirox in rats as biological model. J. Appl. Toxicol., 31, 139-143.

26. Fatemi, S.J., Saljooghi, A.S., Balooch, F.D., Iranmanesh, M. and Golbafan, M.R. (2011) Chelation of cadmium by combining deferasirox and deferiprone in rats. Toxicol. Ind. Health, 27, 371-377.

27. Amiri, A., Fatemi, S.J. and Fatemi, S.N. (2007) Removal of thallium by combining desferrioxamine and deferiprone chelators in rats. Biometals, 20, 159-163.

28. Tubafard, S. and Fatemi, S.J. (2008) Chelation of bismuth by combining desferrioxamine and deferiprone in rats. Toxicol. Ind. Health, 24, 235-240.

29. Iranmanesh, M., Fatemi, S.J., Ebrahimpour, R. and Balooch, F.D. (2013) Chelation of chromium(VI) by combining Deferasirox and deferiprone in rats. Biometals, 26, 465-471. 